\title{
INTOXICAȚIA ACUTĂ CU TUBERCULOSTATICE: RECUNOAŞTERE ŞI TRATAMENT
}

\author{
Dr. Dora Andreea Boghițoiu, Prof. Dr. Coriolan Emil Ulmeanu \\ Spitalul Clinic de Urgență pentru Copii ,, Grigore Alexandrescu“, Bucureşti \\ Catedra de Pediatrie, Universitatea de Medicină şi Farmacie „,Carol Davila“, Bucureşti
}

\begin{abstract}
REZUMAT
Introducere. Deşi frecvența intoxicațiilor cu izoniazidă nu este una foarte mare, reprezintă condiții amenințătoare de viață care necesită recunoaştere şi instituire promptă a tratamentului.

Material şi metodă. Autorii prezintă cazul unei paciente în vârstă de 15 ani care se internează în clinica noastră prin transfer dintr-o altă unitate medicală pentru convulsii tonico-clinice generalizate, urmate de vărsături şi comă. Pacienta este primită în Unitatea Primiri Urgențe a spitalului nostru în comă, Glasgow 8, intubată orotraheal. Nu răspunde la stimuli verbali, dar răspunde prin agitație marcată la stimuli dureroşi profunzi. Are sondă nazogastrică pe care se exteriorizează lichid portocaliu, iar pe sonda urinară - urini de culoare portocalie. Pupilele sunt egale, intermediare, reactive. Reflexe osteotendinoase sunt prezente bilateral. Nu are semne de iritație meningeană şi nici semne neurologice de focar. Din istoricul medical al pacientei, obținut de la mamă, am reținut că pacienta se afla de 4 luni în tratament cu medicamente tuberculostatice (izoniazidă, rifampicină şi vitamina B6). Pacienta îşi administra singură medicamentele.

Rezultate. Pe baza manifestărilor clinice: convulsii tonico-clonice generalizate, vărsături incoercibile şi comă, a aspectului roşu-portocaliu al lichidului gastric şi al urinii la mai mult de 6 ore de la debut, a istoricului medical al pacientei şi al analizelor paraclinice care decelează acidoză metabolică se ridică suspiciunea de intoxicație acută cu tuberculostatice. S-a început administrarea de tratament antidotic cu vitamina B6 cu evoluție favorabilă. Concluzii. Intoxicația acută cu izoniazidă trebuie suspectată la orice pacient care prezintă triada clasică: convulsii refractare, acidoză metabolică severă şi comă, iar tratamentul antidotic cu piridoxină trebuie sa fie disponibil în orice serviciu de urgențe.
\end{abstract}

Cuvinte cheie: izoniazidă, acidoză metabolică, convulsii generalizate, intoxicație, vitamina B6

\section{INTRODUCERE}

Conform Centrului European pentru Prevenirea şi Controlul Bolilor (ECDC), România continuă să ocupe primul loc între statele Uniunii Europene cu cele mai multe cazuri de tuberculoză.

Izoniazida, hidrazida acidului nicotinic, reprezintă prima linie terapeutică în tratamentul şi profilaxia tuberculozei atât la adult, cât şi la copil. Rifampicina este un alt medicament tuberculostatic, cu acțiune sinergică cu a izoniazidei, cu care se asociază în cadrul schemelor terapeutice.

\section{PREZENTARE CAZ}

Pacientă, în vârstă de 15 ani, se internează în clinica noastră prin transfer dintr-o altă unitate medi- cală pentru convulsii tonico-clinice generalizate, urmate de vărsături şi comă. Debutul manifestărilor a fost brusc, în plină stare de sănătate, cu un episod de convulsii tonico-clonice generalizate, cu durată de aproximativ 4-5 minute, urmate de vărsături incoercibile. Familia solicită ambulanța care o transportă la cea mai apropiată unitate medicală, unde pacienta prezintă un nou episod de convulsii tonicoclonice generalizate. Este intubată orotraheal, se montează sonda nazogastrică şi urinară, se stabileşte abord venos şi se instituie tratament cu diazepam, perfuzie de reechilibrare hidro-electrolitică şi este transferată în clinica noastră, unde ajunge la aproximativ 6 ore de la debut.

Pacienta este primită în Unitatea Primiri Urgențe a spitalului nostru în comă, Glasgow 8, intubată orotraheal. Nu răspunde la stimuli verbali, dar răs-

Adresa de corespondență:

Asist. Univ. Dr. Dora Andreea Boghițoiu, Spitalul Clinic de Urgență pentru Copii „Grigore Alexandrescu“, B-dul lancu de Hunedoara nr. 30-32, sector 1, Bucureşti

E-mail: doraboghitoiu@yahoo.com 
punde prin agitație marcată la stimuli dureroşi profunzi. Saturație în oxigen în aerul atmosferic 97$98 \%$, murmur vezicular prezent bilateral fără raluri. $\mathrm{AV}=80 \mathrm{bpm}, \mathrm{TA}=148 / 96 \mathrm{mmHg}$. Are sondă nazogastrică pe care se exteriorizează lichid portocaliu, iar pe sonda urinară - urini de culoare portocalie. Pupilele sunt egale, intermediare, reactive. Reflexele osteotendinoase sunt prezente bilateral. $\mathrm{Nu}$ are semne de iritație meningeană şi nici semne neurologice de focar. $\mathrm{Nu}$ a repetat convulsiile pe durata transportului.

Din istoricul medical al pacientei, obținut de la mamă, am reținut că pacienta se afla de 4 luni în tratament cu medicamente tuberculostatice (izoniazidă, rifampicină şi vitamina B6). Pacienta îşi administra singură medicamentele.

Pe baza manifestărilor clinice: convulsii tonicoclonice generalizate, vărsături incoercibile şi comă, a aspectului roşu-portocaliu al lichidului gastric şi al urinii la mai mult de 6 ore de la debut şi a istoricului medical al pacientei, se ridică suspiciunea de intoxicație acută cu tuberculostatice. Primele analize de laborator, recoltate în Unitatea Primiri Urgențe, au detectat prezența acidozei metabolice $\mathrm{pH} 7,24, \mathrm{BE}-8,2 \mathrm{mmol} / \mathrm{l}$, lactat seric $4,6 \mathrm{mmol} / \mathrm{l}$,
HCO3 17,1 mmol/1. Probele funcționale hepatice au identificat hiperbilirubinemie cu predominanța bilirubinei directe, dar cu valori normale ale transaminazelor. De asemenea, creatinfosfokinaza şi glicemia au avut valori peste limita superioară a normalului. Restul analizelor: hemoleucogramă, probe renale, coagulogramă au fost în limite normale, iar examenul toxicologic rapid din urină a fost pozitiv doar pentru benzodiazepine, utilizate pentru cuparea convulsiilor.

Pacienta a fost internată în secția ATI unde a fost detubată şi s-a instituit tratament cu cărbune activat administrat pe sonda nazogastrică, doze seriate la interval de 6 ore, perfuzie endovenoasă cu glucoză şi electroliţi şi tratament antidotic cu vitamina B6 intravenos. La 6 ore de la internarea pe secția de ATI, deoarece starea pacientei s-a ameliorat, nu a mai repetat convulsiile, coma s-a superficializat, iar parametrii hemodinamici erau în limite normale, aşa că s-a decis transferul în Departamentul de Toxicologie.

Analizele paraclinice repetate la 8 ore de la internare au arătat dispariția acidozei ph $7,41, \mathrm{BE}-4$ $\mathrm{mmo} / \mathrm{l}, \mathrm{HCO} 321,1 \mathrm{mmol} / \mathrm{l}$, dar creşterea valorilor bilirubinei, creatinfosfokinazei precum şi creşterea transaminazelor (Tabelul 1), fără modificarea enzi-

TABELUL 1. Date paraclinice în evoluție corelate cu manifestările clinice

\begin{tabular}{|c|c|c|c|c|c|c|c|c|c|c|}
\hline & \begin{tabular}{|c|} 
Interval de \\
referință
\end{tabular} & Internare & 8 ore & 48 ore & 72 ore & Ziua 4 & Ziua 5 & Ziua 6 & Ziua 7 & $\begin{array}{c}\text { Ziua } 8- \\
\text { externare }\end{array}$ \\
\hline $\mathrm{pH}$ & 7,35-7,45 & 7,24 & 7,41 & 7,40 & 7,41 & - & - & - & - & - \\
\hline \begin{tabular}{|l}
$\begin{array}{l}\text { Exces de baze } \\
\mathrm{mmol} / \mathrm{l}\end{array}$ \\
\end{tabular} & $-3-+3$ & $-8,2$ & $-4,9$ & $-1,6$ & $-3,1$ & - & - & - & - & - \\
\hline $\begin{array}{l}\text { Bicarbonat } \\
\mathrm{mmol} / \mathrm{l}\end{array}$ & $18-23$ & 17 & 21,1 & 23 & 21,6 & - & - & - & - & - \\
\hline ALT U/L & $0-34$ & 18 & 19 & 91 & 148 & 228 & 295 & 318 & 231 & 189 \\
\hline AST U/L & $0-31$ & 31 & 60 & 362 & 487 & 742 & 747 & 551 & 237 & 111 \\
\hline $\begin{array}{l}\text { Bilirubina totală } \\
\mathrm{mg} / \mathrm{dl}\end{array}$ & $0,3-1,1$ & 1,21 & 1,72 & 0,65 & 0,44 & 0,29 & 0,37 & 0,39 & 0,47 & 0,51 \\
\hline \begin{tabular}{|l|} 
Bilirubina \\
directă $\mathrm{mg} / \mathrm{dl}$
\end{tabular} & $0-0,30$ & 0,79 & 0,81 & 0,28 & 0,19 & 0,16 & 0,18 & 0,18 & 0,39 & 0,17 \\
\hline \begin{tabular}{|l|} 
Bilirubină \\
indirectă $\mathrm{mg} / \mathrm{dl}$ \\
\end{tabular} & $0-0,85$ & 0,42 & 0,91 & 0,37 & 0,25 & 0,13 & 0,19 & 0,21 & 0,08 & 0,34 \\
\hline FAL U/L & $74-390$ & - & 85 & 80 & 71 & 64 & 59 & 64 & 59 & 65 \\
\hline GGT U/L & $0-32$ & - & 12 & 11 & 12 & 11 & 12 & 15 & 12 & 10 \\
\hline CPK U/L & $0-145$ & 395 & 3152 & 1275 & 1046 & 533 & 1280 & 5076 & 3175 & 1061 \\
\hline Uree mg/dl & $17-43$ & 21 & 18 & 5 & 10 & 21 & 16 & 14 & 15 & 19 \\
\hline $\begin{array}{l}\text { Creatinină } \\
\mathrm{mg} / \mathrm{dl}\end{array}$ & $0,65-1,1$ & 1,31 & 1,02 & 0,9 & 0,81 & 0,84 & 0,87 & 0,86 & 0,82 & 0,87 \\
\hline $\begin{array}{l}\text { Manifestări } \\
\text { clinice }\end{array}$ & & \begin{tabular}{|l} 
Comatoasă, \\
neresponsivă la \\
stimuli verbali şi \\
dureroşi; \\
IOT; \\
Urini roşii \\
portacalii pe sondă \\
urinară; \\
Conținut gastric \\
roşu portacaliu \\
exteriorizat pe \\
sondă nazogastrică. \\
\end{tabular} & $\begin{array}{l}\text { Somnolență } \\
\text { alternând cu } \\
\text { perioade de } \\
\text { agitație; } \\
\text { Respirație } \\
\text { spontană; } \\
\text { Urini roşii } \\
\text { portacalii } \\
\text { pe sondă } \\
\text { urinară. }\end{array}$ & \begin{tabular}{|l|} 
Obnubilată; \\
Stabilă \\
cardio- \\
respirator; \\
Urini normo- \\
crome.
\end{tabular} & $\begin{array}{l}\text { Orientată } \\
\text { temporo- } \\
\text { spațial; } \\
\text { Stabilă } \\
\text { hemo- } \\
\text { dinamic. }\end{array}$ & $\begin{array}{l}\text { Ficat } \\
\text { palpabil, } \\
\text { cu marginea } \\
\text { inferioară } \\
\text { la } 6 \text { cm sub } \\
\text { rebordul } \\
\text { costal. }\end{array}$ & \begin{tabular}{|l|} 
Mialgii \\
la nivelul \\
muscula- \\
turii membre- \\
lor superioa- \\
re şi \\
inferioare.
\end{tabular} & & $\begin{array}{l}\text { Stabilă } \\
\text { clinic. }\end{array}$ & $\begin{array}{l}\text { Conştientă; } \\
\text { Cooperantă; } \\
\text { Echilibrată } \\
\text { cardio- } \\
\text { respirator; } \\
\text { Fără acuze; } \\
\text { Ficat cu } \\
\text { marginea } \\
\text { inferioară } \\
\text { la } 1 \text { cm sub } \\
\text { rebordul } \\
\text { costal. }\end{array}$ \\
\hline
\end{tabular}


melor de colestază: GGT şi fosfatază alcalină. Examenul sumar de urină a evidențiat prezența glucozei, a corpilor cetonici şi a bilirubinei. Ulterior probele paraclinice s-au recoltat zilnic evidențiind instalarea afectării hepatice toxice şi a rabdomiolizei toxice, valorile maxime înregistrându-se în a 5 zi de la ingestie: AST 747 U/L, ALT 295U/L, creatinfosfokinază 5067U/L (Tabelul 1). Ecografia abdominală a decelat un ficat cu dimensiuni normale, dar cu structură difuz modificată, cu aspect micronodular al parenchimului, fără dezorganizare de arhitectonică, restul structurilor examinate având aspect ecografic normal.

În Departamentul de Toxicologie s-a continuat tratamentul cu perfuzie endovenoasă cu glucoză şi electroliți, vitamina B6, $500 \mathrm{mg} /$ zi şi s-a adăugat silimarina şi arginina odată cu apariţia semnelor de afectare hepatică. Evoluția clinică a fost lent favorabilă. Începând cu ziua a doua se suprimă sonda nazogastrică şi urinară, pacienta devenind conştientă, cooperantă, orientată temporo-spațial, având însă asociat dureri musculare la nivelul membrelor superioare şi inferioare, care s-au remis începând cu ziua a şasea de la internare.

Pe parcursul internării pacienta a fost evaluată psihologic şi inițial a negat ingestia voluntară, dar examinarea psihiatrică stabileşte natura autoagresivă a actului recomandându-se la externarea din departamentul de toxicologie transferul către un serviciu de psihiatrie pediatrică.

În ziua a opta de internare, deoarece starea pacientei era net ameliorată şi probele paraclinice arătau o îmbunătățire a funcției hepatice şi o scădere semnificativă a valorilor creatinfosfokinazei, se decide transferul către departamentul de psihiatrie, dar părinții refuză solicitând externarea pacientei.

\section{DISCUȚII}

Izoniazida, hidrazida acidului izonicotinic, a fost introdusă în tratamentul tuberculozei în anul 1952 şi până în prezent este în continuare prima linie terapeutică utilizată pentru tratamentul, dar şi pentru profilaxia infecției TBC. Are o bună absorbție digestivă şi nivelurile plasmatice optime se ating la 1-2 ore de la ingestia unei doze terapeutice. Străbate bariera hematoencefalică şi atinge, la nivelul lichidului cefalorahidian, concentrații similare celor plasmatice. Eliminarea se face pe cale renală în proporție de $75-90 \%$, mai ales sub formă de metaboliți rezultați în urma biotransformării hepatice prin acetilare şi hidroliză.

Rifampicina este un antibacterian cu spectru larg, derivat din rifampicina B extrasă din Strepto- myces mediterranei. Ea este utilizată în tratamentul infecțiilor cu germeni gram pozitivi sau negativi, dar mai ales în infecția micobacteriană în asociere cu izoniazida. Absorbția digestivă este bună şi difuzează rapid în toate țesuturile şi fluidele organismului, inclusiv în lichidul cefalorahidian (1). Eliminarea se face pe cale biliară preponderent, dar şi renală, în formă activă sau ca metabolit activ (dezacetil-rifamicină) sau inactiv (formil-rifamicină). Urinile emise la 3-6 ore de la administrarea de rifampicină sunt colorate în roşu cărămiziu (1).

Principalele organe afectate de ingestia accidentală sau voluntară a unei doze toxice de izoniazidă sunt ficatul şi sistemului nervos, prin intermediul metaboliților hepatotoxici sau prin interacțiunea cu piridoxină. Semnele de toxicitate apar de la doze de $1.500 \mathrm{mg}$. Dozele mai mari de $30 \mathrm{mg} /$ kgcorp sau un nivel seric peste $10 \mathrm{ug} / \mathrm{ml}$ determină apariţia convulsiilor, în timp ce doze de $80-150 \mathrm{mg} /$ kgcorp sunt asociate cu prognostic rezervat şi deces (2). În cazul pacientei prezentate, doza ingerată nu a fost cunoscută şi nu a fost posibilă nici determinarea nivelurilor serice de izoniazidă sau rifampicină.

Piridoxina (vitamina B6), prin metabolitul său activ - piridoxalfosfatul, este un cofactor esențial în generarea acidului gamaaminobutiric (GABA), principalul neurotrasmițător cu rol inhibitor al sistemului nervos. IHN produce un deficit de piridoxină şi de piridoxalfosfat prin creşterea eliminării renale a acesteia, darşi prin inhibiția piridoxinkinazei implicată în generarea metabolitului activ şi, în consecință, scăderea nivelurilor de acid gamaaminobutiric.

Manifestări clinice pot să apară într-un interval de 30 de minute până la 2 ore de la ingestie şi sunt reprezentate de triada clasică: convulsii recurente, acidoză metabolică şi comă (3). Pacienta noastră a prezentat 2 episoade de convulsii tonico-clonice generalizate urmate de comă, iar probele paraclinice recoltate la internare au evidențiat prezența acidozei metabolice şi acumularea de acid lactic, tipice intoxicației cu IHN.

Afectarea hepatică apare secundar producerii şi acumulării la acest nivel a unui metabolit activ, acetilhidrazina. Deoarece producerea acestor metaboliți hepatotoxici este stimulată de către rifampicină, incidența şi severitatea afectării hepatice cresc atunci când cele doua substanțe sunt asociate (4). Rifampicina determină caracteristic creşteri ale bilirubinei şi ale fosfatazei alcaline, iar creşteri ale transaminazelor pot fi determinate atât de rifampicină, cât şi de izoniazidă, dar mai ales de asocierea lor (5). Hepatotoxicitatea rifampicinei a fost des- 
crisă prima dată de către Scheuer în 1974 într-un studiu care a urmărit 11 pacienți aflați în tratament cu rifampicină. (6)

În cazul pacientei am constatat creşterea transaminazelor cu maximum în a 5 a zi de la ingestie ALT $318 \mathrm{U} / \mathrm{L}$, AST $747 \mathrm{U} / \mathrm{L}$, precum şi creşteri ale bilirubinei totale $(1,72 \mathrm{mg} / \mathrm{dl})$ şi conjugate $(0,81 \mathrm{mg} /$ dl), dar fără modificarea enzimelor de colestază. Alte efecte toxice ale rifampicinei descrise în literatură: trombocitopenie, afectarea funcției renale sau sindromul omului roşu, nu au fost constatate la pacienta prezentată.

Rar, în tabloul clinic al intoxicației cu izoniazidă apare rabdomioliza, secundar toxicității directe a izoniazidei sau a metaboliților, dar mai ales ca o consecință a convulsiilor (7 ). Pacienta a avut valori crescute ale creatinfosfokinazei, dar care au înregistrat o evolutie ondulantă: la 8 ore de la internare $\mathrm{CPK}=3152 \mathrm{U} / \mathrm{L}$, după care valorile au început să scadă ajungând în ziua a 3-a la 533 U/L, pentru ca ulterior, odată cu instalarea durerilor musculare la nivelul membrelor superioare şi inferioare, valorile să atingă un maximum de $5067 \mathrm{U} / \mathrm{L}$ în ziua 6 . Această evoluție este similară cu cea a altor cazuri descrise în literatură, în care CPK atinge valorile maxime în zilele 5-6. Deși există corelații semnificative statistic între valorile CPK şi cantitatea de izoniazidă (peste 2,4 grame) precum şi durata crizelor convulsive (8), în cazul pacientei noastre nu am putut stabili o corelație deoarece nu a fost cunoscută cantitatea de izoniazidă şi nici durata exactă a convulsiilor.

Hiperglicemia, glicozuria, cetonuria sunt, de asemenea, modificări care pot să apară în cazul intoxicaţiei cu izoniazidă şi care, împreună cu acidoza metabolică, pot conduce la confuzia cu cetoacidoza diabetică (3). Toate aceste modificări au apărut în cazul prezentat, dar valorile s-au normalizat în primele 48 de ore de la internare.

În cazul unei intoxicații cu izoniazidă, piridoxina (vitamina B6) este antidotul specific, deoarece manifestările clinice - convulsiile, acidoza metabolică şi alterarea stării de conştiență, sunt secundare deficitului de piridoxină şi de piridoxalfosfat- metabolitul său activ. Necesarul de piridoxină depinde de cantitatea de izoniazidă ingerată. Dacă doza este cunoscută, atunci pentru fiecare gram de izoniazidă se administrează 1 gram de piridoxină. Se preferă administrarea intravenoasă dacă preparatul este disponibil, dar se poate administra şi vitamina B6 formă orală pe sondă nazogastrică. În situația în care nu se cunoaşte cantitatea de izoniazidă ingerată, se administrează o primă doză de vitamina B6 de 5 grame intravenos (70 mg/kgcorp la copil), doză care poate fi repetată la nevoie la interval de 5-20 de minute până la cuparea convulsiilor (9). În cazul prezentat nu au fost cunoscute dozele de izoniazidă, rifampicină şi vitamină B6 pe care pacienta le-a ingerat, convulsiile au fost de scurtă durată şi au fost cupate de administrarea de benzodiazepine înainte de a ajunge în clinica noastră, unde pacienta nu a mai repetat convulsiile, motiv pentru care dozele de vitamin B6 au fost administrate într-un regim de $250 \mathrm{mg}$ intravenos la 12 ore.

În afara tratamentului antidotic, restul măsurilor suportive sunt similare celor folosite în cazul oricărei intoxicații acute: securizarea căilor aeriene, obținerea unei linii venoase şi monitorizarea semnelor vitale.

Administrarea de cărbune activat în doze de 1-2 g/kgcorp este recomandată, deoarece acesta adsoarbe eficient izoniazida limitând absorbția acesteia. Pacienta a primit doze seriate de cărbune activat, administrat pe sondă nazogastrică la interval de 6 ore în primele 48 de ore. Creşterea eliminării toxicului prin hemodializă poate fi eficientă deoarece izoniazida se leagă slab de proteinele plasmatice şi are un volum redus de distribuție. Totuşi este rareori necesară deoarece menţinerea unei diureze adecvate este suficientă pentru eliminarea toxicului (10).

Pentru corectarea acidozei metabolice severe, consecință a convulsiilor, dar şi a inhibării de către izoniazidă a lactatdehidrogenazei, este necesară administrarea intravenoasă de bicarbonat de sodiu 1-2 mmol/kgc, dar mai ales cuparea rapidă a convulsiilor prin administrarea de pirodoxină şi anticonvulsivante.

Benzodiazepinele sunt de primă intenție administrate intravenos, deoarece acţionează la nivelul receptorilor GABA potențând efectul piridoxinei. Se foloseşte diazepam în doze de $0,25-0,5 \mathrm{mg} / \mathrm{kg}$ corp până la maximum $10 \mathrm{mg} /$ doză. Fenitoina, acționând prin intermediul canalelor de sodiu şi nu asupra receptorilor GABA are o eficiență limitată în tratarea covulsiilor declanşate de izoniazidă (3). Pacienta a primit 2 doze de diazepam de $10 \mathrm{mg}$ intravenos înainte de internarea în clinica noastră, care au fost suficiente pentru cuparea convulsiilor şi nu a mai necesitat ulterior tratament anticonvulsivant.

Alterarea funcției hepatice, descrisă în intoxicațiile cu izoniazidă sau rifampicină, a apărut şi în cazul pacientei prezentate. Severitatea variază putând evolua către insuficiența hepatică acută care necesită transplant hepatic sau poate produce deces în $20 \%$ dintre cazuri (11). În cazul afectărilor mai 
puțin severe, evoluția este una favorabilă, fără sechele. Pacienta noastră a prezentat o formă moderată de afectare hepatică, cu creşterea transaminazelor şi a bilirubinei, dar fără alterarea funcției de sinteză hepatice. A primit tratament cu silimarină $210 \mathrm{mg} /$ zi în 3 prize pe perioada spitalizării şi s-a recomandat continuarea la domiciliu a tratamentului încă 14 zile.

\section{CONCLUZII}

Deoarece tuberculoza reprezintă, atât la nivel mondial cât şi național, o problemă de sănătate pu- blică, medicamentele tuberculostatice şi mai ales izoniazida, sunt folosite pe scară largă. Deşi frecvența intoxicațiilor cu izoniazidă nu este una foarte mare, reprezintă condiții amenințătoare de viață care necesită recunoaştere şi instituire promptă a tratamentului. Intoxicația acută cu izoniazidă trebuie suspectată la orice pacient care prezintă triada clasică: convulsii refractare, acidoză metabolică severă şi comă. Tratamentul acestor intoxicații presupune decontaminare gastrointestinală, controlul convulsiilor, corectarea acidozei şi administrarea tratamentului antidotic cu piridoxină, care trebuie sa fie disponibil în orice serviciu de urgențe. 